\title{
Vertical transmission of HIV in Belgium: a 1986-2002 retrospective analysis
}

\author{
Tessa Goetghebuer • Edwige Haelterman • \\ Isabelle Marvillet • Patricia Barlow • Marc Hainaut • \\ Assaad Salameh • Roberta Ciardelli • Michele Gerard • \\ Jack Levy
}

Received: 6 November 2007 / Accepted: 6 March 2008/Published online: 5 April 2008

(C) Springer-Verlag 2008

\begin{abstract}
Prophylactic interventions have lead to the reduction of the mother-to-child transmission (MTCT) of human immunodeficiency virus type 1 (HIV-1) to less than $2 \%$ in industrialized countries. The aim of this study was to evaluate the changes over time in vertical transmission according to the standard care of prophylaxis in the practice of a single large reference center and to identify the risk factors for failure. The rate of MTCT decreased progressively from $10 \%$ in $1986-1993$ to $4.7 \%$ in $1999-2002$, reflecting the progressive implementation of newly available means of prevention. During the last period evaluated (1999-2002), where highly active antiretroviral therapy (HAART) prophylaxis was the standard of care, $17 \%$ of women had a viral load between 400 and 20,000 copies $/ \mathrm{ml}$ around delivery and $5 \%$ had a viral load above 20,000 copies $/ \mathrm{ml}$. High viral load and low CD4 lymphocyte count were strongly associated with vertical transmission. The rate of MTCT in women who received HAART for more than one month during pregnancy was $1.7 \%$, compared to $13.3 \%$ in women treated with HAART for less than one month. The risk of vertical transmission in the absence
\end{abstract}

T. Goetghebuer $(\bowtie) \cdot$ E. Haelterman $\cdot$ I. Marvillet $\cdot$ M. Hainaut

A. Salameh $\cdot$ R. Ciardelli $\cdot$ J. Levy

Pediatric Department, CHU Saint-Pierre,

322 rue Haute,

1000 Brussels, Belgium

e-mail: tessa_goetghebuer@stpierre-bru.be

P. Barlow

Gynecology Department, CHU Saint-Pierre,

322 rue Haute,

1000 Brussels, Belgium

M. Gerard

Infectious Disease Department, CHU Saint-Pierre,

322 rue Haute,

1000 Brussels, Belgium of therapy was four times higher than before the era of antiretroviral therapy (ART; $p=0.05$ ). In conclusion, since the prevention of MTCT of HIV with HAART is the standard of care, a short duration or absence of ART during pregnancy linked to late or absent prenatal care is associated with a high risk of transmission. The early detection of HIV-1 infection in pregnant women, and close follow up and support during pregnancy are crucial to the success of the prevention of transmission.

Keywords Vertical transmission · HIV infection .

Pregnancy $\cdot$ Mother-to-child transmission

$\begin{array}{ll}\text { Abbreviations } \\ \text { MTCT } & \text { Mother-to-child transmission } \\ \text { HIV } & \text { Human immunodeficiency virus } \\ \text { ZDV } & \text { Zidovudine } \\ \text { HAART } & \text { Highly active antiretroviral therapy } \\ \text { ART } & \text { Antiretroviral therapy } \\ \text { CDC } & \text { Centers for Disease Control and Prevention } \\ \text { PCR } & \text { Polymerase chain reaction } \\ \text { OR } & \text { Odds ratio } \\ \text { CI } & \text { Confidence interval }\end{array}$

\section{Introduction}

Without any prophylaxis, the mother-to-child transmission (MTCT) rate of the human immunodeficiency virus type 1 (HIV-1) varies from 12 to $20 \%$ in industrialized countries, but reaches 35 to $40 \%$ in Africa, where breast-feeding is the norm $[10,17]$.

Formula feeding was the first measure proposed to reduce the exposure of the newborn to the virus. In 1994, 
the efficacy of zidovudine (ZDV) given to the mother during pregnancy and delivery and to the newborn has been demonstrated to reduce MTCT [2]. In 1998, elective cesarean section has been recommended as an additional effective measure $[6,10,11,13]$. Since 1996, the administration of highly active antiretroviral therapy (HAART) to HIV-infected pregnant women has been progressively generalized in industrialized countries. The combination of these preventive measures have lead to the reduction of MTCT to less than $2 \%[1,12]$.

Between 1986 and 2002, 361 singletons babies born to HIV-infected mothers were followed up from birth in our center. During this period of time, the measures to prevent vertical transmission were made a part of standard care at the time they were implemented in most industrialized countries. This retrospective cohort study was conducted to evaluate the changes over time in the vertical transmission rates.

\section{Methods}

This is a retrospective cohort study on vertical transmission in infants born to HIV-1-infected mothers over the period 1986-2002.

Study population

All 361 singleton babies born alive between 1986 and 2002 from an HIV-1-infected mother and followed up since birth in our center were included in this study; eight twin pairs were excluded.

As the prophylactic measures used changed over time, we divided the whole group into three birth cohorts:

- Births between 1986 and 1993 (cohort 86-93): preventive measures included obstetrical interventions to shorten the duration of membrane rupture and the exposure of the newborn to the mother's blood and vaginal secretions, together with the avoidance of breast-feeding.

- Births between 1994 and 1998 (cohort 94-98): in addition to the above, ZDV was given to the mother during the last trimester of pregnancy, intravenously during delivery and orally to the infant over the first 6 weeks of life. During a short period of time (October 1997 to 1998), the combination of ZDV and lamivudine was used in newborns.

- Births between 1999 and 2002 (cohort 99-02): the recommendation to perform an elective cesarean section at 38 weeks of gestation was introduced for all pregnancies and HAART was given during (at least) the last trimester of pregnancy.
Data collection

The following data were abstracted from the mothers' medical records: ethnicity, parity, maternal age at delivery, time of maternal HIV diagnosis (before pregnancy, during pregnancy, or at delivery), type, and duration of maternal antiretroviral therapy (ART) regimen, viral load, CD4 lymphocyte count and maternal $\mathrm{CDC}$ stage at delivery. The obstetrical data included: date, mode of delivery, gestational age, episiotomy, and time between rupture of the amniotic membranes and delivery. The data from the newborns included: birth weight and diagnosis of HIV infection. Before 1994, viral culture and the persistence of HIV-1-specific antibodies after the age of 18 months were used to establish HIV infection in children, but since 1994, the diagnosis of HIV infection is based on the detection of proviral HIV DNA and/or by the determination of plasma HIV RNA viral load in two separate blood samples (Amplicor method).

\section{Outcome}

The main outcome was the MTCT of HIV. Secondary outcomes were preterm birth $(<37$ weeks of gestation) and low birth weight $(<2,500 \mathrm{~g})$.

Statistical analysis

We computed the risk of vertical transmission of HIV and the risk of preterm birth according to maternal characteristics, preventive measures used, and period. We used logistic regression modeling to estimate the adjusted odds ratios (ORs) for the associations of different interventions implemented during pregnancy with the outcomes. Among 361 pregnancies, 34 were second and four were third consecutive pregnancies to the same mother in the cohort; they were considered as independent events. As data are often missing for the first period (1986-1993), some analyses only included the last two periods.

Statistical significance was assigned by a two-sided alpha level of 0.05 . All $p$-values are two-tailed. Statistical analysis was performed using SPSS version 15.0 (SPSS Inc., Chicago, IL).

\section{Results}

The distribution of the maternal characteristics of the 361 infants included in the study, divided into the time cohorts, is shown in Table 1. Most of the mothers were of subSaharan African origin and had acquired HIV heterosexually. Maternal age and the proportion of non-European mothers increased over time. 
Table 1 Maternal characteristics according to birth cohort

\begin{tabular}{|c|c|c|c|c|}
\hline & $\begin{array}{l}\text { Cohort } 86-93 \\
n=100\end{array}$ & $\begin{array}{l}\text { Cohort 94-98 } \\
n=111\end{array}$ & \multirow[t]{2}{*}{$\begin{array}{l}\text { Cohort 99-02 } \\
n=150\end{array}$} & \multirow[b]{2}{*}{$p$-value } \\
\hline & \multicolumn{2}{|c|}{$n(\%)$, mean (standard deviation) } & & \\
\hline Maternal age (years) & $27.6(4.7)$ & $29.5(4.4)$ & $30.7(5.5)$ & $<0.001$ \\
\hline \multicolumn{5}{|l|}{ Parity } \\
\hline One & $16(21.3 \%)$ & $30(28.0 \%)$ & $50(33.3 \%)$ & \\
\hline Two to three & $41(54.7 \%)$ & $50(46.7 \%)$ & $82(54.7 \%)$ & \\
\hline Four or more & $18(24.0 \%)$ & $27(25.2 \%)$ & $18(12.0 \%)$ & 0.03 \\
\hline Non-European mother & $61(69.3 \%)$ & $86(79.6 \%)$ & $124(84.9 \%)$ & 0.02 \\
\hline \multicolumn{5}{|l|}{ Time of maternal HIV diagnosis } \\
\hline Before pregnancy & & $52(50.5 \%)$ & $88(58.7 \%)$ & \\
\hline During pregnancy & & $48(46.6 \%)$ & $57(38.0 \%)$ & \\
\hline During delivery & NA & $3(2.9 \%)$ & $5(3.3 \%)$ & $0.38 *$ \\
\hline \multicolumn{5}{|l|}{ Maternal CDC stage at delivery } \\
\hline A & & $90(88.2 \%)$ & $98(66.7 \%)$ & \\
\hline $\mathrm{B}$ & & $6(5.9 \%)$ & $39(26.5 \%)$ & \\
\hline $\mathrm{C}$ & NA & $6(5.9 \%)$ & $10(6.8 \%)$ & $<0.001$ \\
\hline \multicolumn{5}{|l|}{ Viral load at delivery (copies/ml) } \\
\hline$\leq 400$ & & & $114(78.1 \%)$ & \\
\hline $401-20,000$ & & & $25(17.1 \%)$ & \\
\hline$>20,000$ & NA & NA & $7(4.8 \%)$ & - \\
\hline CD4 at delivery $<100$ cells $/ \mathrm{ml}$ & NA & $5(5.6 \%)$ & $1(0.7 \%)$ & $0.03 *$ \\
\hline CD4 at delivery $(\text { cells } / \mathrm{ml})^{£}$ & NA & $450(6-1,515)$ & $412(90-1,656)$ & 0.31 \\
\hline
\end{tabular}

*Exact test

${ }^{£}$ Median (min-max) and Mann-Whitney test

$\mathrm{NA}=$ not available

\section{Risk of vertical transmission}

Table 2 describes the outcomes for each birth cohort according to the preventive measures other than avoiding breast-feeding. None of the mothers had ART given during pregnancy between $86-93$, whereas, respectively, $86 \%$ and $95 \%$ of the 94-98 and 99-02 cohorts received antiretroviral prophylaxis. Over the whole period, vertical transmission occurred in 26 of the 361 infants. There was a progressive decline, although not significant, in the risk of vertical transmission between cohort 86-93 and cohort 99-02. A subgroup analysis of the women who did not receive ART during pregnancy showed a strong linear increase over time in the risk of vertical transmission: the risk was $10 / 100$ $(10.0 \%$; $95 \%$ CI: $4.9 \%-17.6 \%)$ in the $86-93$ cohort, $3 / 16$ (18.8\%; $95 \% \mathrm{CI}: 4.0 \%-45.7 \%)$ in the $94-98$ cohort, and

Table 2 Preventive measures and outcomes distribution according to birth cohort

\begin{tabular}{|c|c|c|c|c|}
\hline & $\begin{array}{l}\text { Cohort } 86-93 \\
n=100\end{array}$ & $\begin{array}{l}\text { Cohort 94-98 } \\
n=111\end{array}$ & $\begin{array}{l}\text { Cohort 99-02 } \\
n=150\end{array}$ & $p$-value \\
\hline \multicolumn{5}{|l|}{ Type of ART regimen during pregnancy } \\
\hline No ART & $100(100 \%)$ & $16(14.4 \%)$ & $8(5.3 \%)$ & \\
\hline Mono or dual therapy & $0(0 \%)$ & $94(84.7 \%)$ & $11(7.3 \%)$ & \\
\hline Triple or quadruple therapy & $0(0 \%)$ & $1(0.9 \%)$ & $131(87.3 \%)$ & $<0.001^{\S}$ \\
\hline More than one month of ART during pregnancy & $0(0 \%)$ & $58(59.8 \%)$ & $122(81.3 \%)$ & $<0.001^{\S}$ \\
\hline Elective cesarian section & $8(8.7 \%)$ & $37(33.9 \%)$ & $89(59.7 \%)$ & $<0.001$ \\
\hline Less than $4 \mathrm{~h}$ between rupture of the amniotic membranes and childbirth & $19(57.6 \%)$ & $75(75.8 \%)$ & $130(87.8 \%)$ & $<0.001$ \\
\hline Episiotomy & $19(27.9 \%)$ & $11(10.1 \%)$ & $8(5.4 \%)$ & $<0.001$ \\
\hline Vertical transmission & $10(10.0 \%)$ & $9(8.1 \%)$ & $7(4.7 \%)$ & $0.10^{*}$ \\
\hline Gestational age at birth $<37$ weeks & $12(12.0 \%)$ & $13(11.7 \%)$ & $20(13.3 \%)$ & $0.91^{£}$ \\
\hline Birth weight $<2,500 \mathrm{~g}$ & $13(13.5 \%)$ & $14(12.6 \%)$ & $20(13.3 \%)$ & $0.98^{£}$ \\
\hline
\end{tabular}

*Test for linear trend

${ }^{£}$ Pearson chi-square

${ }^{\S}$-value for the comparison between cohort 94-98 and cohort 99-02 
reached $3 / 8(37.5 \%$; $95 \% \mathrm{CI}: 8.5 \%-75.5 \%)$ in the $99-02$ cohort. Between 1999 and 2002, seven of the 150 infants were infected (4.7\%; 95\%CI: $1.9 \%-9.4 \%)$ : three were born to mothers who did not receive ART prophylaxis because HIV diagnosis was made at delivery, two were born to mothers who received HAART for less than one month, and two to mothers who received HAART for more than one month during pregnancy.

High viral load and low CD4 lymphocyte count were strongly associated with vertical transmission. In the last cohort, among the seven mothers with a viral load $>20,000$ copies $/ \mathrm{ml}$ around the time of delivery, two infants were infected, compared with four infants $(3 \%)$ born to 139 mothers who had a viral load $<20,000$ copies/ml (risk ratio [RR]: 9.9; 95\%CI: $2.2-45.3 ; p=0.027)$. In the period $94-02$, among six mothers who had CD4 lymphocyte count $<100$ cells/ml, three transmissions occurred, compared with 11/ $229(5 \%)$ among the mothers with a higher level of CD4 (RR: 10.4; 95\%CI: 3.9-27.9; $p=0.003$ ).

Table 3 shows the associations between the type and duration of prophylaxis during pregnancy, obstetrical characteristics, and the risk of MTCT. The lowest risk of vertical transmission $(1.7 \%$; 95\%CI: $0.2 \%-6.1 \%)$ was observed for mothers who received HAART for $>1$ month during pregnancy. Among the women who received prophylaxis, the risk of vertical transmission was greater when HAART was administered for $<1$ month as compared to $>1$ month (adjusted $\mathrm{OR}=6.7$ ). Women who received a mono or a dual therapy for $>1$ month during pregnancy had a higher risk of transmission compared with those who received HAART for $>1$ month (adjusted $\mathrm{OR}=2.5$ ), but this difference was not statistically significant. Performing an episiotomy was not a risk factor of vertical transmission after adjustment for treatment.

Table 4 shows the characteristics of mothers and pregnancies where vertical transmission occurred despite ART prophylaxis administered for $>1$ month during pregnancy. In the last three infants, the transmission occurred most probably during delivery, since the first polymerase chain reaction (PCR) obtained at birth was negative. The first mother was severely immunodepressed and reported a poor adherence to treatment and the second received ZDV only during the third trimester. The last two mothers had detectable viral load on delivery.

\section{Risk of preterm delivery}

Table 5 shows the association between the type and duration of ART prophylaxis during pregnancy and preterm delivery. Since the introduction of ART, mothers remaining untreated during pregnancy were more likely to be diagnosed late or to deliver prematurely. Therefore, the reference group we used was the group of women treated with mono or dual therapy.

The risk of preterm delivery ( $<37$ weeks) was higher for women who received HAART and for untreated women compared to women who received mono or dual therapy. Interestingly, this risk was higher in women treated with HAART for $<1$ month compared to women treated with HAART for a longer duration. Among the women treated for $>1$ month, HAART was associated with low birth weight $(<2,500 \mathrm{~g})$ (adjusted OR: 1.4; 95\%CI: $0.4-4.6$ for

Table 3 Crude and adjusted odds ratio (OR) for the risk of vertical transmission according to the type and duration of antiretroviral therapy (ART) during pregnancy and according to obstetrical characteristics (1994-2002)

\begin{tabular}{|c|c|c|c|c|c|}
\hline & Infected infants, $n(\%)$ & Crude OR $(95 \% \mathrm{CI})$ & $p$-value* & Adjusted $^{\mathfrak{f}}$ OR $(95 \% \mathrm{CI})$ & $p$-value* \\
\hline \multicolumn{6}{|l|}{ Type of ART } \\
\hline None & $6 / 24(25.0 \%)$ & $19.0(3.6-101.5)$ & & $25.9(3.5-190.8)$ & \\
\hline Mono or dual therapy $\leq 1$ month & $3 / 28(10.7 \%)$ & $6.8(1.1-43.1)$ & & $6.7(0.8-58.4)$ & \\
\hline Mono or dual therapy $>1$ month & $2 / 64(3.1 \%)$ & $1.8(0.3-13.4)$ & & $2.5(0.3-20.0)$ & \\
\hline Tri or quadri-therapy $\leq 1$ month & $2 / 15(13.3 \%)$ & $8.8(1.1-67.6)$ & & $6.7(0.7-59.7)$ & \\
\hline Tri or quadri-therapy $>1$ month & $2 / 116(1.7 \%)$ & 1.0 & 0.004 & 1.0 & 0.02 \\
\hline \multicolumn{6}{|l|}{ Mode of delivery } \\
\hline Vaginal delivery with episiotomy & $2 / 19(10.5 \%)$ & $2.0(0.4-10.4)$ & & $0.8(0.1-11.0)$ & \\
\hline Vaginal delivery without episiotomy & $4 / 78(5.1 \%)$ & $0.9(0.3-3.2)$ & & $0.4(0.1-2.4)$ & \\
\hline Emergency cesarean section & $3 / 33(9.1 \%)$ & $1.7(0.4-7.0)$ & & $1.7(0.3-9.1)$ & \\
\hline Elective cesarean section & $7 / 126(5.6 \%)$ & 1.0 & 0.73 & 1.0 & 0.57 \\
\hline \multicolumn{6}{|c|}{ Duration between rupture of the amniotic membranes and childbirth } \\
\hline$<4$ & $12 / 205(5.9 \%)$ & 1.0 & & 1.0 & \\
\hline$\geq 4$ & $4 / 42(9.5 \%)$ & $1.7(0.5-5.5)$ & 0.38 & $1.4^{£}(0.3-6.7)$ & 0.65 \\
\hline
\end{tabular}

$\mathrm{OR}=$ odds ratio; $\mathrm{CI}=$ confidence interval

*Wald test

${ }^{£}$ Adjusted for age, parity, ethnicity, and other variables presented in the table (duration between rupture of the amniotic membranes and childbirth was not entered in models simultaneously with the mode of delivery because of colinearity) 
Table 4 Characteristics of mothers and pregnancies where vertical transmission occurred despite ART prophylaxis being administered for longer than 1 month during pregnancy

\begin{tabular}{|c|c|c|c|c|c|c|c|c|c|c|c|c|c|c|c|}
\hline \multirow{2}{*}{$\begin{array}{l}\text { Year } \\
\text { of } \\
\text { birth }\end{array}$} & \multirow{2}{*}{$\begin{array}{l}\text { Age } \\
\text { (years) }\end{array}$} & \multirow[t]{2}{*}{ Ethnicity } & \multirow[t]{2}{*}{ Parity } & \multirow[t]{2}{*}{$\mathrm{BF}$} & \multirow{2}{*}{$\begin{array}{l}\text { HIV } \\
\text { diagnosis }\end{array}$} & \multicolumn{3}{|c|}{ On delivery } & \multicolumn{2}{|l|}{ Treatment } & \multirow[t]{2}{*}{ Compliance } & \multirow[t]{2}{*}{$\mathrm{BF}$} & \multirow{2}{*}{$\begin{array}{l}\text { Delivery } \\
\text { mode }\end{array}$} & \multirow{2}{*}{$\begin{array}{l}\text { First } \\
\text { PCR }\end{array}$} & \multirow{2}{*}{$\begin{array}{l}\text { GA } \\
\text { (weeks) }\end{array}$} \\
\hline & & & & & & $\mathrm{CDC}$ & $\mathrm{VL}$ & CD4 & $\begin{array}{l}\text { During } \\
\text { pregnancy }\end{array}$ & $\begin{array}{l}\text { On } \\
\text { delivery }\end{array}$ & & & & & \\
\hline 1994 & 29 & A & 1 & no & before P & $\mathrm{C} 3$ & NA & 18 & $\begin{array}{l}\text { ZDV 2nd and } \\
\text { 3rd trimester }\end{array}$ & - & poor & no & ECs & NA & 36 \\
\hline 1996 & 30 & E & 1 & no & during $\mathrm{P}$ & A1 & NA & 814 & $\begin{array}{l}\text { ZDV 3rd } \\
\text { trimester }\end{array}$ & $\begin{array}{l}\text { ZDV } \\
\text { IV }\end{array}$ & good & no & VD & neg & 41 \\
\hline 1999 & 37 & A & 1 & no & before $\mathrm{P}$ & B2 & 2,400 & 242 & $\begin{array}{l}\text { HAART 2nd } \\
\text { and 3rd } \\
\text { trimester }\end{array}$ & $\begin{array}{l}\text { ZDV } \\
\text { IV }\end{array}$ & good & no & ECs & neg & 38 \\
\hline 1999 & 40 & A & 3 & no & during $\mathrm{P}$ & A2 & 19,900 & 397 & $\begin{array}{l}\text { HAART 3rd } \\
\text { trimester }\end{array}$ & $\begin{array}{l}\text { ZDV } \\
\text { IV }\end{array}$ & poor & no & ECs & neg & 38 \\
\hline
\end{tabular}

$\mathrm{A}=\mathrm{A}$ frican; $\mathrm{E}=$ European; $\mathrm{P}=$ pregnancy; $\mathrm{VL}=$ viral load; $\mathrm{GA}=$ gestational age; $\mathrm{BF}=$ breast-feeding; $\mathrm{EC}=$ elective cesarean section; $\mathrm{VD}=\mathrm{vaginal}$ delivery; $\mathrm{NA}=$ not available

HAART compared with mono or dual therapy). These associations, however, were not statistically significant.

\section{Discussion}

Since the introduction of antiretroviral prophylaxis during pregnancy, the rate of MTCT of HIV has dramatically decreased in developed countries. In 1994, the PACTG076 study showed that ZDV given to the mother during pregnancy, delivery, and to the newborn could reduce the risk of transmission from $25 \%$ to $8 \%$ [2]. By 1996, combination ART progressively became the standard of care for the prevention of MTCT. In recent studies, the transmission was shown to be reduced to $<2 \%$ in mothers treated with HAART $[3,5]$. Our study aimed primarily at reviewing the impact of prophylactic measures on vertical transmission in a single reference center cohort of infants born to HIV-1-infected mothers between 1986 and 2002.
The decrease in the vertical transmission rate from $10 \%$ in 1986-1993 to $4.7 \%$ in 1999-2002 reflects the progressive implementation of newly available means of prevention. Whilst the transmission rate is $4.7 \%$ globally for the cohort in the era of HAART, it is lower than $2 \%$ in women who received HAART for more than one month during pregnancy.

The timing of the diagnosis has an obvious impact on the feasibility of implementing prophylactic measures to reduce MTCT. During the period $94-02,43 \%$ of the women were diagnosed with HIV infection during pregnancy or at delivery, and 24/261 (9\%) had no antenatal ART prophylaxis: the MTCT rate in this small group of patients was $25 \%$. The risk of vertical transmission in untreated women in the era of HAART was four times higher than in the group of mothers followed before $1994(p=0.05)$. This suggests that factors such as late diagnosis during pregnancy, poor antenatal care, insufficient implementation of preventive interventions associated or not with social

Table 5 Risk of preterm birth ( $<37$ weeks) according to the administration of ART during pregnancy (1986-2002)

\begin{tabular}{|c|c|c|c|c|c|}
\hline & $n(\%)$ & Crude OR $(95 \% \mathrm{CI})$ & $p$-value* & Adjusted $\mathrm{OR}^{\S}(95 \% \mathrm{CI})$ & $p$-value* \\
\hline \multicolumn{6}{|l|}{ Type of treatment during pregnancy } \\
\hline None & $15(12.1 \%)$ & $1.3(0.6-3.0)$ & & $1.4(0.5-4.2)$ & \\
\hline Mono or dual therapy & $10(9.5 \%)$ & 1.0 & & 1.0 & \\
\hline Tri or quadri-therapy & $20(15.2 \%)$ & $1.7(0.8-3.8)$ & 0.43 & $2.5(1.0-6.5)$ & 0.15 \\
\hline \multicolumn{6}{|l|}{ Duration of ART during pregnancy } \\
\hline None & $15(12.1 \%)$ & $1.8(0.4-8.3)$ & & $2.2(0.3-19.1)$ & \\
\hline Mono or dual therapy $\leq 1$ month & $2(7.1 \%)$ & 1.0 & & 1.0 & \\
\hline Mono or dual therapy $>1$ month & $6(9.4 \%)$ & $1.4(0.3-7.1)$ & & $1.4(0.1-13.4)$ & \\
\hline Tri or quadri-therapy $\leq 1$ month & $6(40.0 \%)$ & $8.7(1.5-50.9)$ & & $10.1(1.0-103.2)$ & \\
\hline Tri or quadri-therapy $>1$ month & $13(11.2 \%)$ & $1.6(0.4-7.7)$ & 0.04 & $3.1(0.4-25.9)$ & 0.08 \\
\hline
\end{tabular}

$\mathrm{OR}=$ odds ratio; $\mathrm{CI}=$ confidence interval

*Wald test

$\S$ Adjusted for age, parity, and ethnicity 
precarity play a significant role in vertical transmission. The duration of prophylaxis appeared to play a crucial role in its effectiveness. Among the mothers treated with HAART for $<1$ month, $13.3 \%$ transmitted HIV to their newborn compared with $1.7 \%$ in mothers treated for $>1$ month. Among the women receiving ART for $>1$ month during pregnancy, those who received a mono or a dual therapy tended to have a higher risk of vertical transmission (3.1\%) compared to the women who received HAART $(1.7 \%)$. Due to the lack of power, this difference was not significant, but it persisted after adjustment for other obstetrical interventions, which indicates that it does not only reflect a more systematic implementation of these preventive interventions in the era of HAART.

In agreement with other studies, we showed that MTCT was correlated with high maternal viral load and low CD4 count at delivery $[5,16]$. In our cohort, the rate of transmission was similar in elective cesarean section and in vaginal delivery without episiotomy $(6 \%$ and $5 \%$, respectively). Current guidelines no longer propose cesarean section in mothers with undetectable viral load [9].

Several studies have suggested that the use of HAART during pregnancy was associated with the increased risk of preterm birth $[4,7,14]$, although others could not confirm this observation [15]. We found that HAART administered for a short duration was associated with a higher risk of preterm birth, which could either reflect the lower opportunity of women who deliver preterm in receiving treatment, or represent an acute side-effect of HAART in a subsample of women. Among the women treated for longer periods, the differences between premature delivery between the mother receiving HAART and the mother receiving mono or dual therapy was not significant, and this might possibly be due to lack of the power due to the small sample size. Obviously, there are other maternal factors known to be associated with preterm delivery, including ethnicity, socio-economic factors, illicit drug use, poor quality of the obstetrical follow up, or poor clinical status of the mother. In our cohort, most women were of African origin and living in poor socio-economic situations. The rate of premature birth in this population in Brussels is known to be higher than in the general population $(9.7 \%$ vs. $7.4 \%)$ [8].

In conclusion, HAART given during pregnancy, together with other preventive measures, allows us to dramatically decrease the MTCT of HIV. However, transmission still occurs at a high rate in the subgroup of women who miss the opportunity to benefit from these interventions because of a late diagnosis of HIV infection or poor antenatal care.

Acknowledgment The authors would like to thank the mothers who participated to this study. The Smiles Foundation, Belgium, supported this study.

\section{References}

1. Coll O, Fiore S, Floridia M, Giaquinto C, Grosch-Wörner I, Guiliano M, Lindgren S, Lyall H, Mandelbrot L, Newell ML, Peckham C, Rudin C, Semprini AE, Taylor G, Thorne C, Tovo PA (2002) Pregnancy and HIV infection: a European consensus on management. AIDS 16(Suppl 2):S1-S18

2. Connor EM, Sperling RS, Gelber R, Kiselev P, Scott G, O'Sullivan MJ, VanDyke R, Bey M, Shearer W, Jacobson RL, Jimenez E, O’Neill E, Bazin B, Delfraissy J-F, Culnane M, Coombs R, Elkins M, Moye J, Stratton P, Balsley J (1994) Reduction of maternal-infant transmission of human immunodeficiency virus type 1 with zidovudine treatment. Pediatric AIDS Clinical Trials Group Protocol 076 Study Group. N Engl J Med 331(18):1173-1180

3. Cooper ER, Charurat M, Mofenson L, Hanson IC, Pitt J, Diaz C, Hayani K, Handelsman E, Smeriglio V, Hoff R, Blattner W; Women and Infants' Transmission Study Group (2002) Combination antiretroviral strategies for the treatment of pregnant HIV1-infected women and prevention of perinatal HIV-1 transmission. J Acquir Immune Defic Syndr 29(5):484-494

4. European Collaborative Study; Swiss Mother and Child HIV Cohort Study (2000) Combination antiretroviral therapy and duration of pregnancy. AIDS 14(18):2913-2920

5. European Collaborative Study (2005) Mother-to-child transmission of HIV infection in the era of highly active antiretroviral therapy. Clin Infect Dis 40(3):458-465

6. The European Mode of Delivery Collaboration (1999) Elective caesarean-section versus vaginal delivery in prevention of vertical HIV-1 transmission: a randomised clinical trial. Lancet 353 (9158):1035-1039

7. Grosch-Wörner I, Puch K, Maier RF, Niehues T, Notheis G, Patel D, Casteleyn S, Feiterna-Sperling C, Groeger S, Zaknun D; Multicenter Interdisciplinary Study Group Germany/Austria (2008) Increased rate of prematurity associated with antenatal antiretroviral therapy in a German/Austrian cohort of HIV-1infected women. HIV Med 9(1):6-13

8. Haelterman E, De Spiegelaere M (2007) Les Indicateurs de Santé Périnatale en Région de Bruxelles-Capitale, 1998-2004. In: Rapport Observatoire de la Santé et du Social., Observatoire de la Santé et du Social, Brussels, Belgium. Available online at: http://www.observatbru.be/documents/Perinatalite.pdf

9. Hawkins D, Blott M, Clayden P, de Ruiter A, Foster G, GillingSmith C, Gosrani B, Lyall H, Mercey D, Newell ML, O'Shea S, Smith R, Sunderland J, Wood C, Taylor G; BHIVA Guidelines Writing Committee (2005) Guidelines for the management of HIV infection in pregnant women and the prevention of mother-tochild transmission of HIV. HIV Med 6(Suppl 2):107-148

10. The International Perinatal HIV Group (1999) The mode of delivery and the risk of vertical transmission of human immunodeficiency virus type 1 - a meta-analysis of 15 prospective cohort studies. N Engl J Med 340(13):977-987

11. Landers DV, Duarte G (1999) Mode of delivery and the risk of vertical transmission of HIV-1. N Engl J Med 341(3):205-207

12. Newell ML, Thorne C (2004) Antiretroviral therapy and motherto-child transmission of HIV-1. Expert Rev Anti Infect Ther 2 (5):717-732

13. Rowland BL, Vermillion ST, Soper DE (2001) Scheduled cesarean delivery and the prevention of human immunodeficiency virus transmission: a survey of practicing obstetricians. Am J Obstet Gynecol 185(2):327-331

14. Townsend CL, Cortina-Borja M, Peckham CS, Tookey PA (2007) Antiretroviral therapy and premature delivery in diagnosed HIVinfected women in the United Kingdom and Ireland. AIDS 21 (8):1019-1026 
15. Tuomala RE, Shapiro DE, Mofenson LM, Bryson Y, Culnane M, Hughes MD, O'Sullivan MJ, Scott G, Stek AM, Wara D, Bulterys M (2002) Antiretroviral therapy during pregnancy and the risk of an adverse outcome. N Engl J Med 346(24):1863-1870

16. Warszawski J, Tubiana R, Le Chenadec J, Blanche S, Teglas JP, Dollfus C, Faye A, Burgard M, Rouzioux C, Mandelbrot L; ANRS French Perinatal Cohort (2008) Mother-to-child HIV transmission despite antiretroviral therapy in the ANRS French Perinatal Cohort. AIDS 22(2):289-299

17. The Working Group on Mother-To-Child Transmission of HIV (1995) Rates of mother-to-child transmission of HIV-1 in Africa, America, and Europe: results from 13 perinatal studies. J Acquir Immune Defic Syndr Hum Retrovirol 8 (5):506-510 